\title{
ANALISIS TINGKAT KEMATANGAN GONAD TERIPANG KELING (Holothuria atra) DI PERAIRAN MENJANGAN KECIL, KARIMUNJAWA
}

\author{
Analysis of Maturity Rate of Gonad Lollyfish (Holothuria atra) in Menjangan Kecil Island, Karimunjawa
}

\author{
Malasari Harahap, Bambang Sulardiono*), Djoko Suprapto \\ Program Studi Manajemen Sumberdaya Perairan \\ Departemen Sumberdaya Akuatik Fakultas Perikanan dan Ilmu Kelautan, Universitas Diponegoro \\ J1. Prof. Soedharto, SH, Tembalang, Semarang, Jawa Tengah-50275 \\ Emil : malmalaa5@gmail.com
}

\begin{abstract}
ABSTRAK
Pulau Menjangan Kecil berada di perairan Laut Jawa tepatnya di Kecamatan Karimunjawa, Kabupaten Jepara. Perairan Menjangan Kecil memiliki keindahan alam bawah laut yang menarik dan memiliki potensi perikanan yang menyebabkan perairan ini menjadi tempat untuk dilaksanakannya penelitian. Salah satu contoh hasil perikanan dari Perairan Menjangan Kecil yang bisa diandalkan adalah Teripang Keling. Teripang Keling (Holothuria atra) merupakan spesies yang mudah dikenal dan seringkali menjadi spesies yang dominan dalam suatu ekosistem, karena memiliki warna tubuh hitam, kulit tubuhnya licin dan tebal. Tujuan penelitian ini adalah untuk mengetahui tingkat kematangan gonad Holothuria atra dan mengetahui pengaruh parameter fisika, kimia terhadap kematangan gonad Holothuria atra di Perairan Menjangan Kecil, Karimunjawa. Penelitian dilaksanakan pada bulan Mei 2017 di Perairan Menjangan Kecil, Karimunjawa. Metode yang digunakan adalah metode observasi, yaitu kegiatan mengamati sampel secara langsung. Penelitian ini menggunakan data primer dan data sekunder. Data primer didapatkan melalui pengamatan langsung di lapangan dan analisis di laboratorium. Data sekunder diperoleh dari instansi pemerintah dan warga sekitar Pulau Menjangan Kecil, Karimunjawa. Penelitian ini dilakuan pada 4 stasiun dan 12 titik. Hasil pengamatan tingkat kematangan gonad Holothuria atra tergolong pada tahap perkembangan dan pengaktifan. Tingkat salinitas $34 \mathrm{ppt}$, suhu berkisar $29-31{ }^{\circ} \mathrm{C}, \mathrm{pH} 8$ dan kedalaman antara $63-124 \mathrm{~cm}$.
\end{abstract}

\section{Kata Kunci : Tingat Kematangan Gonad, Teripang Keling (Holothuria atra), Perairan Menjangan Kecil}

\begin{abstract}
Menjangan Kecil Island was located in Java Sea precisely in District Karimunjawa, Jepara, Central Java. Menjangan Kecil Island has an attractive natural underwater beauty and has fishery potential that causes these waters to be a place for conducting research. One example of fishery products from Menjangan Kecil Island that can be relied was Lollyfish. Lollyfish (Holothuria atra) was a species that was easy to recognized and it's dominant species in ecosystem, because it has a black body, skin of the body slippery and thick. The purpose of this study was to determine the maturity rate of gonad Holothuria atra and to explain the influence of physical, chemical parameters on the maturity of the gonad Holothuria atra in Menjangan Kecil Island, Karimunjawa. This research has been done in May 2017 at Menjangan Kecil Island, Karimunjawa. The method used was observating method. This research used primary data and secondary data. Primary data were obtained through direct field observating and laboratory analysis. Secondary data obtained from government agencies and residents around Menjangan Kecil Island, Karimunjawa. This research was conducted in 4 stations and 12 points. The maturity level of the Holothuria atra gonad was classified as the stage of development and activation. The salinity level was $34 \mathrm{ppt}$, the temperature ranges from $29-31^{\circ} \mathrm{C}$, pH 8 and the depth of sea water was between $63-124 \mathrm{~cm}$.
\end{abstract}

Keywords: Maturity Rate of Gonad, Lollyfish (Holothuria atra), Menjangan Kecil Island

*) Penulis penanggungjawab

\section{PENDAHULUAN}

Pulau Menjangan Kecil berada di perairan Laut Jawa tepatnya di Kecamatan Karimunjawa, Kabupaten Jepara, Provinsi Jawa Tengah dengan luas wilayah 43.025 ha. Posisi geografis pulau Menjangan Kecil adalah pada $05^{\circ} 53^{\prime} 10^{\prime}$ 0553’50” Lintang Selatan, 110²6’55” - 110²9’36” Bujur Timur. Pulau Menjangan Kecil merupakan salah satu pulau

${ }^{\circ}$ Copyright by Management of Aquatic Resources (MAQUARES) 
kecil yang bersebelahan dengan Karimunjawa. Perairan Menjangan Kecil memiliki potensi perikanan yang menyebabkan perairan ini menjadi tempat untuk dilaksanakannya penelitian. Keindahan alam bawah lautnya yang menarik, banyak biota yang saling interaksi, seperti bermacam ikan, teripang, bulu babi, sand dollar dan juga bintang laut. Salah satu contoh hasil perikanan dari Perairan Menjangan Kecil, Karimunjawa yang bisa diandalkan adalah Teripang Keling. Teripang Keling (H. atra) memiliki ciri-ciri penampang tubuh bulat, sisi ventral yang cenderung datar. Warna tubuh hitam, kulit tubuhnya lembut dan tebal. Biasanya ditemukan di daerah bersubstrat pasir dan tubuhnya diselimuti oleh pasir halus.

Teripang Keling (H. atra) merupakan jenis biota laut yang domestik di perairan Menjangan Kecil. Teripang ini mampu hidup (berkembang biak) secara baik pada perairan yang jernih dan berpasir. Reproduksi merupakan salah satu faktor yang dapat dipergunakan sebagai dasar atau indikasi bagi evaluasi pengelolaan sumberdaya perairan, khususnya bagi kelangsungan hidup dan keturunan suatu organisme atau populasi. Maka perlu dilakukan pengamatan analisa tingkat matang gonad pada H. atra. Hal ini diperkuat oleh Purwati (1996) dalam Sulardiono (2011), mengatakan bahwa kesinambungan kehidupan semua makhluk hidup (termasuk teripang) di alam terjadi melalui aktivitas perkembangbiakan atau reproduksi dan aktivitas ini merupakan suatu proses alamiah yang bertujuan untuk mempertahankan keberadaannya di alam. Reproduksi ini juga dapat dipengaruhi oleh faktor lingkungan, antara lain siklus bulan dan habitat hidup H. atra.

Berdasarkan proses reproduksi, sebelum terjadi pemijahan, sebagian besar hasil metabolisme tertuju untuk perkembangan gonad. Gonad semakin bertambah berat dibarengi dengan semakin bertambah besar ukurannya. Berat gonad akan mencapai maksimum sesaat teripang akan berpijah, kemudian berat gonad akan menurun dengan cepat selama pemijahan sedang berlangsung sampai selesai. Tingkat kematangan gonad adalah tahap perkembangan gonad sebelum dan sesudah teripang memijah. Sedangkan indeks kematangan gonad berguna untuk mengetahui perubahan yang terjadi dalam gonad tersebut secara kuantitatif. Jenis teripang ini jarang ada yang mengkonsumsi karena rasanya pahit, sehingga harganya relatif murah. Tahun 2015 telah banyak peneliti yang mengamati bahwa $H$. atra memiliki kandungan ekstrak yang bisa dijadikan untuk obat. Rasa pahit yang terkandungan dalam tubuh $H$. atra ini sebenarnya sangat berguna karena ekstrak $H$. atra mengandung alkaloid, steroid dan triterpenoid serta saponin. Potensi senyawa bioaktif yang dimiliki $H$. atra ini dapat dimanfaatkan sebagai bahan baku dibidang biofarmaka. Sehingga terjadi permintaan yang meningkat akan produksi $H$. atra. Akibat dari meningkatnya permintaan pasar akan $H$. atra maka areal penangkapan teripang semakin luas, menurunnya stok teripang di alam dan terjadinya degradasi habitat teripang yang dikarenakan polusi pada saat penangkapan. Untuk mengatasi hal tersebut, maka dapat dilakukan dengan cara mengetahui tingkat kematangan gonad $H$. atra dan mengurangi penangkapan yang berlebihan.

Berdasarkan uraian diatas, manfaat yang didapatkan dari penelitian ini adalah dapat memberikan informasi mengenai analisis tingkat kematangan gonad $H$. atra dan mengetahui pengaruh parameter fisika, kimia terhadap kematangan gonad $H$. atra yang selanjutnya informasi ini dapat digunakan untuk mendukung pengelolaan sumberdaya perikanan khususnya $H$. atra di Karimunjawa. Tujuan dari penelitian ini adalah untuk mengetahui tingkat kematangan gonad $H$. atra dan pengaruh parameter fisika, kimia terhadap kematangan gonad H. atra di Perairan Menjangan Kecil, Karimunjawa.

\section{MATERI DAN METODE PENELITIAN}

Materi yang digunakan pada penelitian ini adalah Teripang Keling $(H$. atra) yang berasal dari Pulau Menjangan Kecil, Karimunjawa. Metode yang digunakan dalam penelitian ini adalah metode observasi, yaitu kegiatan mengamati sampel secara langsung, dengan memperhatikan kondisi lingkungan serta populasi sampel. Menurut Kriyantono (2008), mengatakan bahwa Metode Observasi merupakan metode pengumpulan data yang digunakan pada penelitian kualitatif. Seperti penelitian kualitatif lainnya, observasi difokuskan untuk mendeskripsikan dan menjelaskan fenomena yang terjadi ketika melaksanakan penelitian atau riset.

\section{a. Teknik Sampling}

Teknik sampling menggunakan metode simple random sampling adalah sampling acak sederhana. Simple random sampling yaitu teknik penentuan lokasi dan sampel secara acak dengan menentukan jumlah sampel yang akan diteliti, memberikan nomor urut pada semua satuan sampel yang diambil serta dapat mewakili wilayah penelitian dalam pengambilan sampel secara keseluruhan. Menurut Sugiyono (2012), Simple random sampling merupakan metode yang digunakan untuk memilih sampel dari populasi secara acak sederhana sehingga setiap anggota populasi mempunyai peluang yang sama besar untuk diambil sebagai sampel. Seluruh anggota populasi menjadi anggota dari kerangka sampel. Simple random sampling biasa digunakan jika populasi bersifat homogen. Cara pengambilan sampel bisa 
dilakukan dengan acak yaitu, memilih individu sampel dan lokasi yang akan digunakan secara acak untuk mewakili populasi dan wilayah secara keseluruhan.

Penentuan lokasi sampling dilakukan dengan menentukan 4 stasiun dan 12 titik yang akan dijadikan objek penelitian. Pengambilan data dilakukan pada saat surut terendah, agar dapat memudahkan dalam pengambilan data. Kemudian menentukan tiitik koordinat menggunakan GPS.

Tabel 1. Koordinat Stasiun Lokasi Penelitian

\begin{tabular}{cccc}
\hline Stasiun & Titik & Lintang Selatan & Titik Koordinat \\
& 1 & $5^{\circ} 53^{\prime} 16.82^{\prime \prime}$ & $110^{\circ} 24^{\prime} 44.48^{\prime \prime}$ \\
A & 2 & $5^{\circ} 53^{\prime} 17.50^{\prime \prime}$ & $110^{\circ} 24^{\prime} 44.08^{\prime \prime}$ \\
& 3 & $5^{\circ} 53^{\prime} 16.09^{\prime \prime}$ & $110^{\circ} 24^{\prime} 45.61^{\prime \prime}$ \\
& 1 & $5^{\circ} 53^{\prime} 31.56^{\prime \prime}$ & $110^{\circ} 24^{\prime} 49.79^{\prime \prime}$ \\
B & 2 & $5^{\circ} 53^{\prime} 30.06^{\prime \prime}$ & $110^{\circ} 24^{\prime} 47.56^{\prime \prime}$ \\
& 3 & $5^{\circ} 53^{\prime} 30.91^{\prime \prime}$ & $110^{\circ} 24^{\prime} 51.57^{\prime \prime}$ \\
& 1 & $5^{\circ} 53^{\prime} 32.54^{\prime \prime}$ & $110^{\circ} 24^{\prime} 19.51^{\prime \prime}$ \\
C & 2 & $5^{\circ} 53^{\prime} 34.51^{\prime \prime}$ & $110^{\circ} 24^{\prime} 19.11^{\prime \prime}$ \\
& 3 & $5^{\circ} 53^{\prime} 31.42^{\prime \prime}$ & $110^{\circ} 24^{\prime} 18.02^{\prime \prime}$ \\
& 1 & $5^{\circ} 53^{\prime} 8.89^{\prime \prime}$ & $110^{\circ} 24^{\prime} 32.29^{\prime \prime}$ \\
& 2 & $5^{\circ} 53^{\prime} 9.79^{\prime \prime}$ & $110^{\circ} 24^{\prime} 30.82^{\prime \prime}$ \\
\hline
\end{tabular}

Sumber : Hasil penelitian tahun 2017

Berikut adalah gambaran lokasi penelitian beserta titik pengambilan sampel yang ditunjukkan oleh gambar 1 .

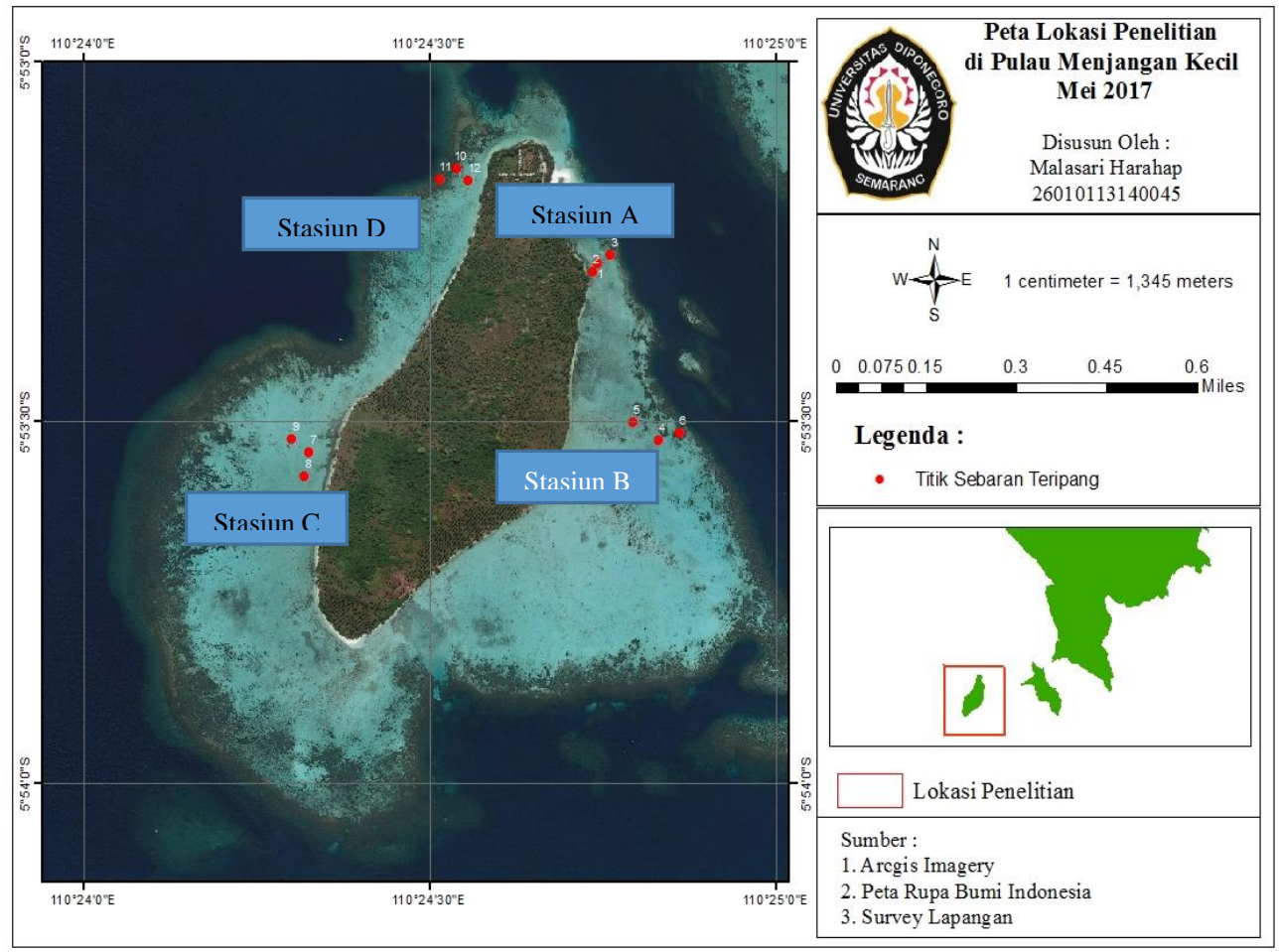

Gambar 1. Peta Lokasi Sampling

Keempat stasiun tersebut menyebar di beberapa wilayah Perairan Menjangan Kecil sesuai dengan peta penyebaran stasiun yang dapat dilihat pada Gambar 2. Pada lokasi stasiun A adalah ekosistem lamun yang terletak disebelah timur Pulau Menjangan Kecil yang disekitarnya terdapat dermaga. Pada lokasi stasiun B adalah ekosistem terumbu karang yang terletak disebelah selatan pulau menjangan kecil yang tidak terdapat kegiatan pariwisata. Pada lokasi stasiun C adalah ekosistem lamun yang terletak disebelah barat Pulau Menjangan Kecil yang tidak terdapat kegiatan pariwisata. Pada lokasi stasiun D adalah ekosistem terumbu karang yang terletak disebelah utara Pulau Menjangan Kecil yang terdapat kegiatan pariwisata. 
Pengambilan data lapangan berupa, sampel $H$. atra, sedimen dan data parameter fisika-kimia. Pada penelitian lapangan dilakukan pengambilan sampel $H$. atra yang ditetapkan dalam 4 stasiun dan setiap stasiun dibagi menjadi 3 titik (I, II, III). Mengambil sampel teripang berdasarkan jumlah ketersediaan teripang di lapangan dan sudah ditetapkan setiap stasiun hanya diambil 3 ekor sampel $H$. atra. Serta melakukan pengukuran parameter fisika-kimia (yaitu : suhu air, $\mathrm{pH}$, salinitas, kedalaman, kecerahan dan arus) dan pengambilan substrat dasar disetiap titik perstasiun. Sampel $H$. atra ditimbang berat basahnya, kemudian dimasukkan dalam coolbox yang sudah diisi dengan air laut dan formalin (agar sampel awet). Pengambilan data parameter kualitas air adalah sebagai data pendukung untuk memberikan gambaran kondisi lingkungan perairan lokasi penelitian pada saat penelitian sedang dilaksanakan.

b. Teknik labolatorium

Pada pengamatan di laboratorium melakukan pembedahan guna mengetahui kematangan gonad. Metode pembedahan $H$. atra dilakukan dengan cara membelah teripang pada bagian bawah tubuh, dari anus menuju ke mulut. Setelah di bedah, kemudian menimbang berat gonad menggunakan timbangan elektrik (gram). Data yang diperoleh kemudian dianalisis. Untuk mendapatkan nilai indeks kematangan gonad dengan menggunakan rumus dari (Effendi, 1997)

$\mathrm{IKG}=\mathrm{Bg} / \mathrm{Bt} \times 100 \%$

Selanjutnya melakukan pengamatan gonad seperti warna, morfologi dengan bantuan mikroskop dan menganalisis data dengan indeks gonad somatik (GSI).

\section{HASIL DAN PEMBAHASAN}

Hasil penelitian yang didapatkan dengan menganalisis tingkat kematangan gonad $H$. atra di Perairan Menjangan Kecil, Karimunjawa adalah sebagai berikut :

Indeks Kematangan Gonad

Tabel 2 . Indeks Kematangan Gonad H. atra di Perairan Menjangan, Karimunjawa

\begin{tabular}{ccccc}
\hline \multirow{2}{*}{ Stasiun } & Spesies & \multicolumn{2}{c}{ Berat Tubuh dan Gonad } & IKG $(\%)$ \\
& & Tubuh (gr) & Gonad (gr) & \\
\hline A & 1 & 200,44 & 4,49 & 2,24 \\
& 2 & 176,94 & 3,1 & 1,75 \\
& 3 & 170,91 & 2,67 & 1,56 \\
B & 4 & 180,28 & 3,47 & 0,92 \\
& 5 & 150,29 & 1,46 & 0,65 \\
& 6 & 140,37 & 0,91 & 2,31 \\
C & 7 & 192,24 & 4,45 & 1,21 \\
& 8 & 164,86 & 2,0 & 0,63 \\
& 9 & 130,11 & 0,82 & 1,80 \\
D & 10 & 188,38 & 3,4 & 0,67 \\
& 11 & 141,79 & 0,95 & 0,61 \\
\hline
\end{tabular}

Sumber : Hasil Penelitian tahun 2017

Menurut Hasil analisis IKG diatas, menunjukkan bahwa rata-rata indeks kematangan gonad tertinggi terdapat pada stasiun A dan nilai rata-rata indeks kematangan gonad terendah berada di stasiun D. 


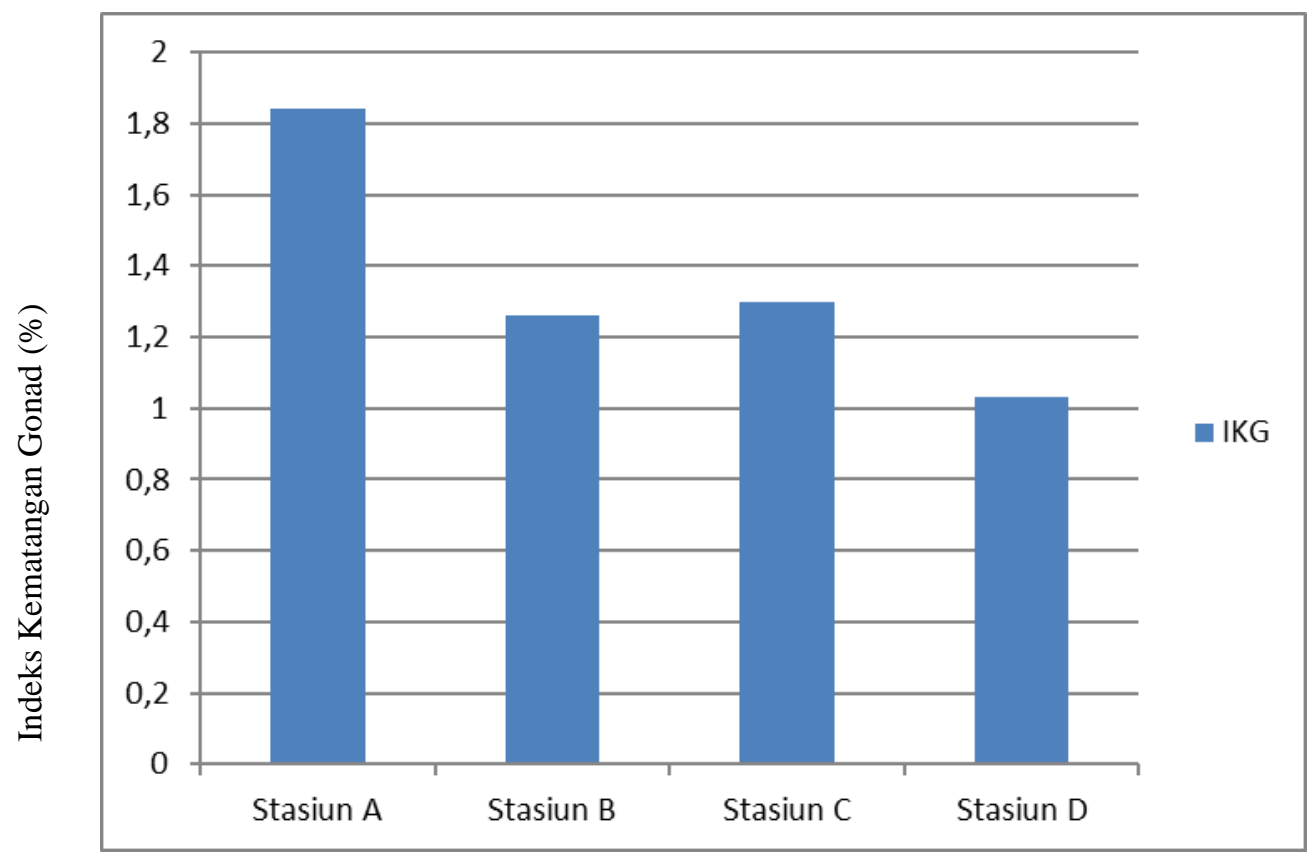

Gambar 2. Rata-rata IKG pada masing-masing stasiun

\section{Tingkat Kematangan Gonad}

Tabel 3. Tingkat Kematangan Gonad H. atra berdasarkan Tahap Perkembangan

\begin{tabular}{|c|c|c|c|c|}
\hline \multicolumn{2}{|c|}{ Tahap Perkembangan } & \multicolumn{2}{|l|}{ Ciri - ciri } & Jumlah \\
\hline \multicolumn{2}{|c|}{ Pertumbuhan } & \multicolumn{2}{|c|}{$\begin{array}{l}\text { - Gonad kosong } \\
\text { - Bobot gonad sekitar } 0 \text { - 0,6 gram } \\
\text { - IKG kurang dari } 1 \%\end{array}$} & Tidak ada \\
\hline \multicolumn{2}{|c|}{ Perkembangan } & \multicolumn{2}{|c|}{$\begin{array}{l}\text { - Bobot gonad berkisar } 0,7-2,0 \text { gram } \\
\text { - IKG kurang dari } 1 \%\end{array}$} & 5 \\
\hline \multicolumn{2}{|c|}{ Pengaktifan } & \multicolumn{2}{|c|}{$\begin{array}{l}\text { - Bobot gonad } 2-5 \text { gram } \\
\text { - Warna gonad kuning atau orange } \\
\text { - IKG } 1-3 \%\end{array}$} & 7 \\
\hline \multicolumn{2}{|c|}{ Pematangan } & \multicolumn{2}{|c|}{$\begin{array}{l}\text { - Bobot gonad } 10 \text { gram } \\
\text { - IKG } 10 \%\end{array}$} & Tidak ada \\
\hline \multicolumn{2}{|l|}{ Pemijahan } & \multicolumn{2}{|c|}{$\begin{array}{l}\text { - Bobot gonad lebih dari } 60 \text { gram } \\
\text { - IKG lebih dari } 10 \%\end{array}$} & Tidak ada \\
\hline \multicolumn{5}{|c|}{$\begin{array}{l}\text { Sumber : Hasil Penelitian tahun } 2017 \\
\text { Keterangan : }\end{array}$} \\
\hline \multicolumn{5}{|c|}{ Lapisan Sedimen } \\
\hline \multirow{2}{*}{ Stasiun } & \multicolumn{4}{|c|}{ Persentase Lapisan Sedimen (\%) } \\
\hline & Pasir Kasar & Pasir Sedang & Pasir Halus & Lumpur \\
\hline A & 47,66 & 27,74 & 14,20 & 10,40 \\
\hline B & 57,74 & 23,34 & 11,18 & 7,74 \\
\hline $\mathrm{C}$ & 48,28 & 28,06 & 14,20 & 9,46 \\
\hline $\mathrm{D}$ & 65,71 & 20,59 & 8,79 & 4,91 \\
\hline
\end{tabular}

Sumber : Hasil Penelitian tahun 2017 
Variabel Fisika dan Kimia

Tabel 5. Variabel Fisika dan Kimia Perairan di Pulau Menjangan Kecil

\begin{tabular}{lcccc}
\hline & \multicolumn{4}{c}{ Hasil } \\
\cline { 2 - 5 } Variabel Fisika Kimia & Stasiun A & Stasiun B & Stasiun C & Stasiun D \\
\hline Suhu Air $\left({ }^{\circ} \mathrm{C}\right)$ & 29 & 30 & 29 & 31 \\
Kedalaman $(\mathrm{cm})$ & 124 & 90 & 102 & 63 \\
Kecerahan & $\tilde{0}$ & $\sim$ & $\tilde{0}$ & $\tilde{0}$ \\
Kecepatan Arus $(\mathrm{m} / \mathrm{s})$ & 0,05 & 0,1 & 0,05 & 0,1 \\
Ph & 8 & 8 & 8 & 8 \\
Salinitas $(\% 00)$ & 34 & 34 & 34 & 34 \\
\hline
\end{tabular}

Sumber : Hasil Penelitian tahun 2017

\section{Pembahasan}

Tingkat kematangan gonad $H$. atra pada stasiun A terdapat 3 ekor teripang yang telah memasuki tahap pengaktifan gonad. Tahap pengaktifan gonad teripang dicirikan dengan berat gonad berkisar antara $2-5$ gram dan warna gonad sudah terlihat kuning. Berdasarkan penelitian ini tingkat matang gonad pada stasiun A tergolong dalam tahap pengaktifan, dilihat dari berat gonad $H$. atra tertinggi yaitu, 4,49 gram dan terendah adalah 2,67 gram. Sedangkan pada stasiun $C$ terdapat 2 ekor teripang sedang dalam tahap pengaktifan, dengan berat gonad tertinggi 4,45 gram dan 1 ekor teripang sedang dalam tahap perkembangan. Stasiun A dan $\mathrm{C}$ adalah stasiun, dimana kondisi suhu air tergolong optimun untuk kelangsungan hidup $H$. atra, yaitu $29^{\circ} \mathrm{C}$. Suhu air sangat mempengaruhi kondisi $H$. atra, dimana suhu dan salinitas sangat berperan penting pada tahap matang gonad teripang.

Stasiun B terdapat 1 ekor teripang yang sedang dalam tahap pengaktifan dan 2 ekor teripang dalam tahap perkembangan. Berat gonad teripang terkecil dan sedang dalam tahap perkembangan adalah 0,91 gram. Hal ini sesuai dengan ciri-ciri tingkat matang gonad Yu (1984) dalam Mustopa (2014) menyatakan bahwa berat gonad berkisar 0,2 2,0 gram berada pada tahap perkembangan dengan nilai indeks kematangan gonadnya tidak kurang dari $1 \%$. Pada stasiun B kondisi suhu air laut tidak stabil, suhunya mencapai $31^{\circ} \mathrm{C}$. Akibatnya mempengaruhi matang gonad $H$. atra menjadi lambat, sehingga nilai indeks kematangan gonadnya kecil. Kedalaman air pada stasiun ini juga tergolong dangkal yang menyebabkan suhu air tergolong tinggi. Stasiun D dari 3 ekor sampel teripang, terdapat 1 ekor teripang sedang dalam tahap pengaktifan dengan berat gonad 3,4 gram dan 2 ekor teripang lainnya sedang dalam tahap perkembangan. Berat gonad terkecil dari semua sampel $H$. atra pada penelitian ini terdapat di stasiun D, dengan nilai berat gonad 0,73 gram.

Perbedaan berat gonad dan nilai IKG teripang pada masing-masing stasiun tersebut dapat terjadi karena faktor lingkungan dan ketersediaan makanan pada masing-masing stasiun. Stasiun A dan B memiliki kondisi pantai yang didominasi lamun dan terumbu karang, patahan terumbu karang, alga dan partikel pasir yang halus, sedangkan stasiun C dan D didominasi dengan pasir dan partikel pasir pecahan karang. Menurut Sutaman (1993) dalam Saputra et al., (2012), makanan utama teripang yaitu deposit pasir yang terdapat pada daerah terumbu karang, potongan serasah karang atau detritus yang terdapat dalam lumpur atau pasir.

Berdasarkan penelitian ini, sulit di temukan $H$. atra yang sedang dalam tahap pemijahan. Hal ini dikarenakan $H$. atra merupakan hewan nocturnal yang artinya hewan tersebut akan keluar dan mencari makan pada malam hari. Waktu pengambilan sampel $H$. atra tidak bersamaan dengan waktunya $H$. atra keluar dan mencari makan. Alangkah baiknya pengambilan sampel $H$. atra dilakukan pada tengah malam atau menjelang pagi. Hal ini di jelaskan oleh Fetcher (1974) dalam Saputra et al., (2012), bahwa pemijahan teripang umumnya berlangsung pada malam hari sampai menjelang pagi, sebelum matahari terbit.

Berdasarkan pengukuran suhu di keempat stasiun hasilnya menunjukkan bahwa, semakin tinggi nilai suhu air, maka semakin kecil nilai dari indeks kematangan gonad. Sebab, suhu air sangat mempengaruhi kematangan gonad $H$. atra. Pengukuran suhu air pada stasiun A dan $\mathrm{C}$ tergolong suhu optimum yaitu $29^{\circ} \mathrm{C}$, dimana pada suhu tersebut optimum untuk kelangsungan hidup H.atra. Sedangkan suhu yang paling tinggi berada pada stasiun D dengan nilai $31^{\circ} \mathrm{C}$, maka dengan suhu tersebut mempengaruhi matang gonad, sehingga kematangan gonadnya lambat dan suhu pada stasiun ini kurang baik untuk kelangsungan hidup $H$. atra. Kemudian pada stasiun $\mathrm{B}$, rata-rata suhunya $30^{\circ} \mathrm{C}$ juga tergolong tinggi untuk kelangsungan hidup teripang, sebab metabolismenya terganggu oleh cahaya yang masuk kedalam perairan (menyebabkan air laut makin hangat) dan matang gonadnya terhambat. $H$. atra di stasiun A memiliki rata-rata IKG yang tertinggi dibandingkan dengan rata-rata IKG di stasiun yang lainnya, hal ini mengindikasikan adanya pengaruh suhu terhadap indeks kematangan gonad teripang, yaitu perairan dengan suhu normal merupakan perairan yang sangat baik bagi kehidupan teripang. Hal ini dapat disebabkan karena suhu di stasiun A adalah suhu yang 
paling sesuai untuk kehidupan H. atra. Hal ini diperkuat oleh Mustopa (2014), menjelaskan bahwa temperatur dan salinitas merupakan 2 faktor yang sangat berpangaruh pada reproduksi teripang.

Hasil pengukuran $\mathrm{pH}$ air di keempat stasiun sama, yaitu 8 dan begitu juga dengan persentase salinitas, keempat stasiun sama-sama memiliki salinitas sebesar 34 ppt dengan kecerahan tak terhingga (seluruh perairan masih dapat ditembus oleh cahaya matahari). Kedalaman perairan di keempat stasiun menunjukkan adanya perbedaan kedalaman. Stasiun dengan kedalaman cukup dalam ada pada stasiun A, sedangkan stasiun dengan kedalaman rendah ada pada stasiun D. Selanjutnya dari segi kecepatan arus, arus terbesar pada stasiun B dan D sedangkan arus terkecil berada pada stasiun A dan C.

Persentase lapisan sedimen didapat bahwa pasir kasar lebih banyak pada stasiun yang lebih dekat dengan pantai, seperti stasiun D. sedangkan pasir sedang, persentase paling banyak ada pada stasiun C. Persentase pasir dengan ukuran halus paling banyak ada pada stasiun A dan C. Persentase lumpur paling banyak ada pada stasiun A. Subtrat dasar perairan pada tiap stasiun adalah sama yaitu pasir berlumpur dan pecahan karang. Ada juga di temui rumput laut tumbuh subur. Menurut Martoyo et al., (1994) dalam Mustopa (2014), karang dan rumput laut selain berfungsi sebagai pelindung juga berfungsi sebagai perangkap makanan untuk teripang. Berkaitan dengan cara makan teripang yaitu deposite feeder, maka teripang akan lebih menyukai subtrat yang banyak mengandung plankton, detritus dan bahan organik.

\section{KESIMPULAN SARAN SARAN}

Kesimpulan dari hasil penelitian ini adalah tingkat kematangan gonad $H$. atra di Perairan Menjangan Kecil, Karimunjawa tergolong pada tahap perkembangan dan pengaktifan. $H$. atra pada tingkat pengaktifan paling banyak ditemukan di stasiun A dan C, sedangkan di stasiun B dan D tergolong pada tahap perkembangan. Parameter fisika dan kimia yang paling berpengaruh pada tingkat kematangan gonad $H$. atra adalah suhu air laut.

Saran yang dapat disampaikan dari penelitian yang berjudul Analisis Tingkat Kematangan Gonad Teripang Keling $(H$. atra) di Perairan Menjangan Kecil, Karimunjawa adalah sebaiknya penelitian selanjutnya diharapkan dapat melakukan analisis TKG dengan jenis teripang yang lebih dari 1 dan sebaiknya penelitian selanjutnya diharapkan dapat melakukan penelitian mengenai teripang di lokasi perairan yang berbeda.

\section{UCAPAN TERIMAKASIH}

Ucapan terimakasih ditujukan kepada Dr. Ir. Suryanti, M.Pi dan Churun A'in, S.Pi, M.Si yang telah memberikan saran dan kritik yang sangat bermanfaat bagi penulis. Kepada semua pihak yang telah membantu sehingga penulis dapat menyelesaikan artikel ini.

\section{DAFTAR PUSTAKA}

Effendi. M. I. 1997. Metode Biologi Perikanan. Yayasan Pustaka Dwi Sri. Bogor.

Kriyantono, Rachmat. 2008. Teknik Praktis Riset. Kencana Prenada Media Grup.

Martoyo, J, Aji N, dan T. Winanto. 2006. Budidaya Teripang. Penebar Swadaya, Jakarta.

Mustopa, Arif 2014. Frekuensi Kematangan Gonad Teripang (Holothuroidea) Di Pantai Bandengan Kabupaten Jepara. Jurnal DISPROTEK. 5 (1).

Poppo, A., Mahendra, M.S., dan Sundra, K.I. 2007. Studi Kualitas Perairan Pantai di Kawasan Industri Perikanan. Dinas Pengambengan.Kecamatan Negara. Kabupaten Jembrana. Jurnal. Unud. Bali.

Saputra, A., E. Gunaisah, F. Ardianta, S. Andriyanto. 2012. Pengembangbiakan Aseksual Teripang Keling (Holothuria atra) di Kampung Manyaifun, Raja Ampat, Papua Barat. Media Akuakultur 7(2) : 71-72.

Sugiyono. 2012. Metode Penelitian Kombinasi (Mixed Methods). CV. Alfabeta, Bandung, 630 hlm .

Sulardiono, B. 2011. Kematangan Gonad Teripang Komersial Stichopus Vastus (Holothuriidea : Stichopodidae) Di Perairan Karimunjawa, Kabupaten Jepara, Jawa Tengah. Jurnal Saintek Perikanan 7(1):24 - 31. 